\title{
Feasibility of Applying Artifact-Metrics to Fine Wooden Lacquerware
}

\author{
Masaki Fujikawa and Shingo Fuchi
}

\begin{abstract}
We explored the feasibility of applying artifact-metrics to authenticate and identify valuable, fine lacquerware. We used a model method to consider the feasibility of this technique. In this method, lacquer liquid containing fine particles with optical properties was utilized several times to coat the base material for lacquerware so that the fine particles randomly occurred in the coating film of the lacquer. As information resulting from the optical properties of fine particles can be obtained in a contactless manner by photo shooting, the risk of degrading or scratching the surface of lacquerware by using this method is low. In the experiment using the above model, we used clear lacquer liquid that contained glass phosphor powder and coated it onto wooden base material to make sample lacquerware. We acquired an infrared (IR) image of each sample by optical excitation and found that the fine particles randomly occurred and formed a layer. The intensity of the IR light emission was determined based on the number of times the lacquer liquid was coated on the wooden base material.
\end{abstract}

Index Terms-Authentication, artifact-metrics, image processing, fine wooden lacquerware.

\section{INTRODUCTION}

\section{A. Background and Aim}

Fine craft products differ from ordinary personal items used in daily life as they are elaborately designed with beautiful patterns and colors. These products are sometimes related to intellectual and esthetic hobbies; examples include textiles, ceramics, and wooden works. The production of fine craft products is costly and time consuming. Specifically, fine crafts produced by renowned artists and manufacturers or in famous production areas are likely to have high prices as they have traditionally been popular among collectors.

Reproductions that imitate the appearances and textures of fine craft products are traded at affordable prices in markets. Although the imitations are manufactured by using economical materials at low cost, differentiating fine craft products from their counterpart reproductions at a glance is considered to be difficult. Consequently, imitations disguised as fine craft products are often sold at equivalent price in markets. As a result, consumers are likely to experience

Manuscript received November 10, 2015; revised January 10, 2016. This work was supported in part by the Kurata Memorial Hitachi Science and Technology Foundation.

Masaki Fujikawa is with the ALSOK, Ishijima 2-14, Koto-ku, Tokyo 135-0014 Japan (e-mail: markie-special-agent@nifty.com).

Shingo Fuchi is with the Department of Electrical Engineering and Electronics, Aoyama Gakuin University, 5-10-1 Fuchinobe, Chuo-ku, Sagamihara-shi, Kanagawa 252-5258 Japan. economical and emotional damage when they unknowingly purchase reproductions believing them to be fine products [1].

Fine, high-priced lacquerware and affordable imitations are sold alongside each other in markets. According to the Japanese Household Goods Quality Labeling Act [2], lacquerware is categorized into two groups: "lacquerware" and "synthetic resin lacquered ware." The lacquerware category represents products coated with natural lacquer liquid. In contrast, the synthetic resin lacquered ware category represents products coated with synthetic resin coatings. Lacquerware and synthetic resin lacquered ware are further classified into four types, as shown in Table I.

TABLE I: FINE CLASSIFICATION OF LAQCUERWARE

\begin{tabular}{cl}
\hline \hline Type & \multicolumn{1}{c}{ Brief overview } \\
Type 1 & $\begin{array}{l}\text { The natural wooden base material is coated by natural } \\
\text { lacquer liquid. This type of product is designated as fine } \\
\text { wooden lacquerware. }\end{array}$ \\
\hline Type 2 & $\begin{array}{l}\text { The base material is coated by synthetic resin and is made } \\
\text { from wood powder or synthetic resin and formed by press } \\
\text { machines. }\end{array}$ \\
\hline Type 3 & $\begin{array}{l}\text { The base material is coated by several types of synthetic } \\
\text { resin. The base material contains a natural wooden base } \\
\text { and the artificial base described in Type 2. }\end{array}$ \\
\hline Type 4 & $\begin{array}{l}\text { Although the base material is coated with synthetic resin } \\
\text { during the manufacturing process, a natural lacquer liquid } \\
\text { is used as the top coat. The base material contains a natural } \\
\text { wooden base and the artificial base described in Type } 2 .\end{array}$ \\
\hline \hline
\end{tabular}

Fine wooden lacquerware is made from a natural wood base coated by natural lacquer liquid. Although synthetic resin lacquered ware is categorized as a lacquerware, the same as fine wooden lacquerware, these products are made from cheap materials; the base material is made from wood powder and/or synthetic resin that is coated with synthetic resin coating material. According to Table I, lacquerware types 2, 3, and 4 correspond to imitation lacquerware.

The selling of imitation lacquerware is not illegal if the seller explicitly indicates that the products are imitations using phrases such as "This product is not fine wooden lacquerware," or "This product is synthetic resin lacquered ware." However, people are likely to recognize imitation lacquerware as fine wooden lacquerware when they have poor abilities to distinguish lacquerware, as the differences between their appearances are not obvious. Subsequently, consumers tend to economically and emotionally suffer if synthetic resin lacquered ware is sold as fine wooden lacquerware [3].

In general, fine wooden lacquerware is coated with black or colored pigment natural lacquer liquid. Some pieces are coated with non-pigmented natural lacquer liquid. In the latter case, the wood grain on the wooden base material differs for each product and is visually inspected; this type of 
lacquerware is primarily authenticated manually, in contrast to fine wooden lacquerware, for which biometric authentication systems are utilized. (In those systems, physical features such as fingerprints, irises, and vein patterns are used to identify persons individually). For example, before shipment, the manufacturer takes an image of a specific area of the fine wooden lacquerware and stores it in a safe database as a registered image. If the manufacturer is asked to authenticate the product, the manufacturer acquires an image of that specific area of the product in question, compares it with the registered image, and determines whether the image matches that of the registered fine wooden piece.

However, the aforementioned method cannot be applied to lacquerware that does not have wood grain or cannot be visually inspected. In addition, counterfeit wooden products with wood grain imitating that of fine wooden pieces are on the market [4], [5]; subsequently, consumers, in addition to the abovementioned authentication methods, could mistake the copied products for fine wooden lacquerware if the counterfeit lacquerware contains wood grain that imitates that of fine wooden lacquerware.

There exists a need for a technique that can distinguish fine wooden lacquerware from synthetic resin lacquered ware during the distribution process to prevent consumers from wrongly purchasing imitations instead of fine products. If the said technique can identify each fine product automatically, consumers can purchase valuable fine wooden lacquerware with peace of mind, as they can specify the lacquerware's information, such as its production date, production serial number, and manufacturer or artist.

Here, we present the results of our evaluation to determine the feasibility of using artifact-metrics on fine wooden lacquerware to verify its authenticity and identify individual wooden lacquerware pieces. In Section II, we present basic information about lacquerware and the prerequisite information needed to understand the scope of this paper. In Section III, we introduce the model method used for our study to explore the feasibility of using artifact-metrics for fine wooden lacquerware. In Section IV and Section V, we describe our experiment and discuss its results. A summary is presented in Section VI.

\section{B. Artifact-Metrics}

Artifact-metrics [6] are employed to authenticate artifacts by using characteristic information generated accidentally and spontaneously in the manufacturing process and to verify their authenticity (in a method similar to biometric authentication) by comparing the registered and extracted information from the object in question by using measuring equipment. The artifact-metric system involves the implementation of artifact-metrics (see Fig. 1). In this system, reference data is generated from characteristic information that is extracted from the object and stored in a database. During the authentication process, characteristic information is extracted from the object and compared with the reference data to determine whether the product is genuine. Afterwards, the verification result is shown. As the said system is considered to be secure, the results cannot be altered, and the reference data cannot be maliciously leaked.

Microscopically, characteristic information from each product varies, but extracting that information is not a trivial task. Technically, it is possible to extract the said information using a microscope; however, it is time consuming to specify an imaging area for registration and authentication as such imaging areas are microscopically small. (For example, the visual field of a half-inch CCD camera with a magnifying lens $(10 \times)$ is $0.48 \mathrm{~mm} \times 0.64 \mathrm{~mm}$.) Accordingly, for artifact-metrics, an organic or inorganic material is added during the manufacturing process to extract the characteristic information from objects easily, as such materials have unique optical, electromagnetic, electronic, or vibrational properties. The extracted information is then used to authenticate the artifact [5].

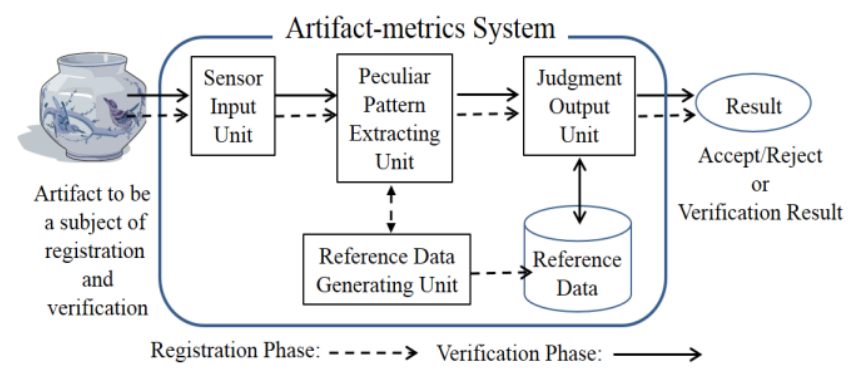

Fig. 1. Outline of artifact-metric system.

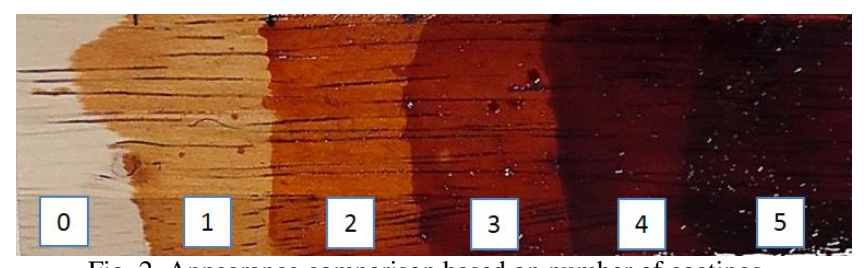

Fig. 2. Appearance comparison based on number of coatings.

\section{Related Study: Application of Artifact-Metrics to Ceramics}

We previously proposed a technique to authenticate daily produced valuable ceramics by using artifact-metrics [7]. For this prior technique, we made a fine powder of transparent glass phosphor, which emits near-infrared light by optical excitation, and added it to the glaze or paint to weld glass phosphor particles onto the ceramics in the furnace $\left(1,200-1,300{ }^{\circ} \mathrm{C}\right)$ during the firing process. We used the size and thickness of the glass phosphor particles generated in the furnace spontaneously and accidentally as the characteristic information. This information was extracted by infrared (IR) imaging, as the said information was reflected as the intensity of the IR light emission caused by optical excitation. Hence, each product could be authenticated by comparing the registered and extracted images.

The abovementioned method cannot be applied to fine wooden lacquerware to generate characteristic information spontaneously and accidentally as such products are manufactured at room temperature. Consequently, we developed a model method for fine wooden lacquerware to generate and extract appropriate characteristic information.

\section{BASIC INFORMATION AND PREREQUISITES}

In this section, we present basic information about lacquerware and prerequisites to clarify the scope of this paper. 


\section{A. Basic Information (Manufacturing Process and Features of Fine Wooden Lacquerware)}

Although manufacturing differs as it depends on the manufacturer or artist and the production area, it generally consists of six processes (see Table II). The color and gloss of the lacquer's coated film on the product increases when the intermediate coating and polishing are repeated several times. Fig. 2 shows the results of a preliminary experiment wherein the clear lacquer coating was successively applied. (Clear lacquer liquid is made from refined lacquer tree sap and is a clear amber color, as shown in Fig. 2. Black lacquer liquid is made by adding iron powder to clear lacquer, resulting in the oxidation of the lacquer liquid and a color change to black. Colored lacquer liquid is made by adding colored pigment to clear lacquer liquid.) We observed that the color and gloss of the coated film increased when the number of coatings increased.

Lacquerware is used for tableware and ornaments, as lacquer's coated film remains unaltered by acid, alkali, salt, and alcohol. However, leaving lacquerware outdoors should be avoided as ultraviolet rays easily affect the coated film.

\begin{tabular}{ll}
\multicolumn{1}{c}{ TABLE II: MANUFACTURING OF LACQUERWARE } \\
\hline \hline No. & \multicolumn{1}{c}{ Process } \\
\hline 1 & $\begin{array}{l}\text { Polishing 1: Polish the base material for the lacquerware by using } \\
\text { fine-grain sandpaper. }\end{array}$ \\
\hline & $\begin{array}{l}\text { Undercoating: Coat the base material with lacquer liquid. Harden } \\
\text { the lacquer's coating film by storing in a place with high humidity. } \\
\text { (Natural lacquer hardens and forms the coating film to absorb the } \\
\text { moisture. In contrast, synthetic resin coating material forms the } \\
\text { coating film to evaporate the moisture. This is one of the major } \\
\text { differences between fine wooden lacquerware and synthetic resin } \\
\text { lacquerware.) Polish the said film by using cotton fabric. }\end{array}$ \\
\hline 3 & $\begin{array}{l}\text { Polishing 2: Polish the lacquer's coating film by using fine-grain } \\
\text { sandpaper. }\end{array}$ \\
\hline 4 & Intermediate coating: Same as No. 2. \\
\hline 5 & Polishing: Same as No. 3. \\
\hline 6 & Final coating: Same as No. 2. \\
\hline \hline
\end{tabular}

\section{B. Prerequisites}

Herein, we define prerequisites to clarify the scope of our discussion.

1) In this experiment, clear lacquer liquid was used in process Nos. 2, 4, and 6 in Table II. This choice was made so that we could easily observe the impact of the added material on the formation of the characteristic information on the product. We were able to observe with the naked eye how the material affected the color and gloss of the clear lacquer's coating film. Thus, lacquerware with black or colored lacquer liquid is out of the scope of our discussion.

2) In this study, we set the number of coatings using the clear lacquer liquid as follows: undercoating: 1, intermediate coating: 3 , and final coating: 1 . Hence, the clear lacquer liquid was coated five times on the base lacquer material. This choice was made because the recommended total number of coatings for the intermediate coating process was three when we interviewed several manufacturers. We omitted the polishing process shown in Table II, as the aim of this study was to confirm the feasibility of using artifact-metrics.

\section{Model ARTIFACT-Metrics FOR FINE WOODEN LACQUERWARE}

In this section, we discuss the feasibility of applying the artifact-metrics technique to fine wooden lacquerware by using a model method.

\section{A. Model Method}

We developed this method based on the usage of lacquer liquid to coat the base lacquer material several times and the existence of the traditional decollating method for fine wooden lacquerware known as "Ma-ki-e" in Japanese. Ma-ki-e is a technique that adds gold or silver powder on the lacquer coating film just after lacquering until the film hardens. This technique is used to add the grace and form patterns on the product.

By using this method, characteristic information is randomly formed and in laminae as the clear lacquer liquid is coated on the base material several times along with fine luminous powder. Because glass phosphor powder is used, characteristic information (the intensity of IR light emission) is extracted in a contactless manner by using an IR camera, as it emits IR light (peak wavelength 1,000 nm) upon optical excitation.

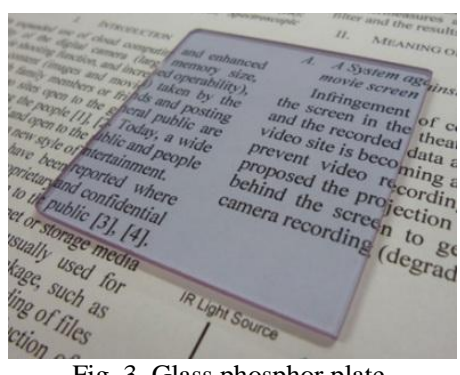

Fig. 3. Glass phosphor plate.

Advantages of the abovementioned method are given below.

1) As the characteristic information is formed randomly and in laminae on the fine wooden lacquerware, images with different intensities of IR emission can be obtained for specific areas by changing the camera viewpoint. This phenomenon will ensure the uniqueness of each product and is able to determine if strong correlations between the registered and extracted characteristic information exist during the verification process. (If a strong correlation exists between them, identifying each product is possible even though the photographic condition is slightly changed. In this method, the phenomenon in which the intensity of IR light emission differs based on the viewpoint is used [6].) This phenomenon also makes copying products difficult (refer to Section III.A).

2) IR light is used as the light source of the optical excitation instead of ultraviolet rays so that the coated film will not be affected. In addition, characteristic information can be obtained in a contactless fashion, so the quality of the product is not impaired by scratches, stains, and breakage while extracting the needed information. In addition, glass phosphor presents no safety risks to humans or to the environment [7].

3) As each manufacturing process of the fine wooden lacquerware (see Fig. 2) is assigned to a specific professional craftsperson, asking for a craftsperson to 
complete an additional task is not appropriate because it would be out of the scope of his or her own routine work. The model method does not require additional work for any craftsperson, as the manufacturing processes are not changed except in that characteristic information is extracted.

4) The model method is used to observe the intensity of IR light emission by optical excitation of the material added to the object. Hence, this method differs from the other methods mentioned in Appendix, as these methods detect the reflection and transmission components of the irradiated light while the object is irradiated by a light source.

\section{B. Difficulty of Imitation Production}

Counterfeiters may think that the amount of IR rays can be adjusted by selecting and accumulating particles properly. We will, therefore, explain the difficulty of creating identical characteristic information in this manner. Simplistically, we can assume three types of particles with respect to the passage of IR light (see Fig. 4) and that counterfeiters only intend to emit IR light along the Z-axis (see Fig. 5).

In reality, emitted IR rays from particle (1) may have another three passes that could be observed in another space (XY-, YZ-, or ZX-space) because of the boundaries of neighboring particles (see Fig. 6). Furthermore, particles are not spherical (they have random asperity), which makes it quite difficult to adjust the number of IR rays by selecting and accumulating particles in an effort to mirror the IR spectral image of a genuine product.

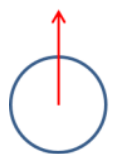

(1)

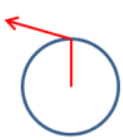

(2)

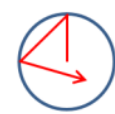

(3)
Fig. 4. IR light passage.

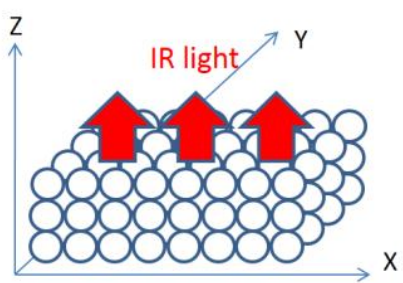

Fig. 5. IR light emission along Z-axis.

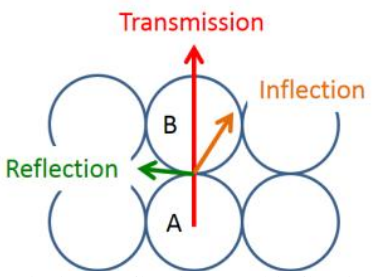

Fig. 6. Transmission, reflection, and inflection of IR rays.

As the glass phosphor particles are arranged randomly and in a layered state on the product, images taken by an IR camera from various viewpoints will be different. Accordingly, it is quite difficult to adjust the intensity of IR light emission by controlling the position of each fine particle with several micrometers even if a counterfeiter obtains a genuine wooden lacquerware piece, takes IR images from various viewpoints, and tries to accumulate particles on the surface of a synthetic resin lacquerware piece while referring to the genuine images.

\section{EXPERIMENT}

In this section, we describe the elementary experiment that was conducted using the model method described in Section III to explore the feasibility of applying artifact-metrics to fine wooden lacquerware.

\section{A. Experiment 1: Generation of Characteristic Information}

We manually prepared the glass phosphor powder by using a mortar and muddler. For comparison, we also produced an ordinary glass powder without IR emission. Next, we prepared three types of mixed lacquer liquid, and each had different weight percentages of clear lacquer liquid and glass phosphor powder. In this paper, " $10 \%$ glass phosphor" means that the mixed liquid contained $90 \%$ clear lacquer liquid and $10 \%$ glass phosphor powder. Likewise, "5\% glass phosphor" contained 95\% clear lacquer liquid and 5\% glass phosphor power, and " $1 \%$ glass phosphor" comprised $99 \%$ clear lacquer liquid and 1\% glass phosphor powder. Similarly, we made three types of mixed lacquer liquid with ordinary glass powder. Herein, " $10 \%$ glass" refers to a mixture of $90 \%$ clear lacquer liquid and $10 \%$ glass powder. Likewise, "5\% glass" contains $95 \%$ clear lacquer liquid and $5 \%$ glass powder, and "1\% glass" comprises $99 \%$ clear lacquer liquid and $1 \%$ glass powder. We also prepared the base wooden material (width: $35 \mathrm{~mm}$, length: $120 \mathrm{~mm}$, and thickness: $13 \mathrm{~mm}$ ), polished it with sandpaper, and made samples in accordance with the process described in section 2.1 by changing the area and number of clear lacquer liquid and mixed liquid coatings (see Fig. 7). We used brushes to coat the liquids onto the base wooden material. We confirmed that the existing film coating had hardened well before we applied a new coat of liquid on the film.

Fig. 8 shows the sample coated with clear lacquer liquid. Fig. 9 shows the sample coated with clear lacquer liquid with ordinary glass powder. Fig. 10 shows the sample coated with clear lacquer liquid with glass phosphor powder. Each sample exhibits increasing color and gloss with increasing number of coatings. The two powders were stable in the coated films. The films did not detach when we rubbed the surface with our fingers.

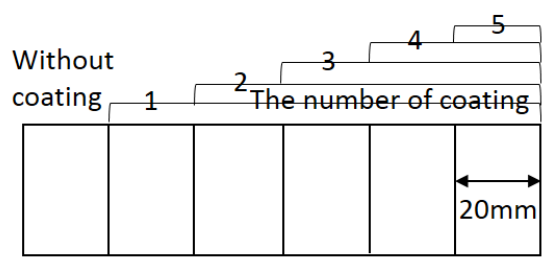

Base wooden material

Fig. 7. Method of coating mixed and clear lacquer liquid.

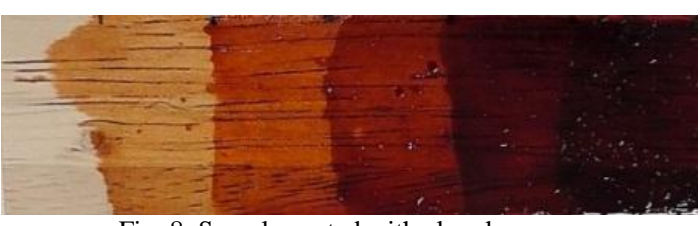

Fig. 8. Sample coated with clear lacquer. 

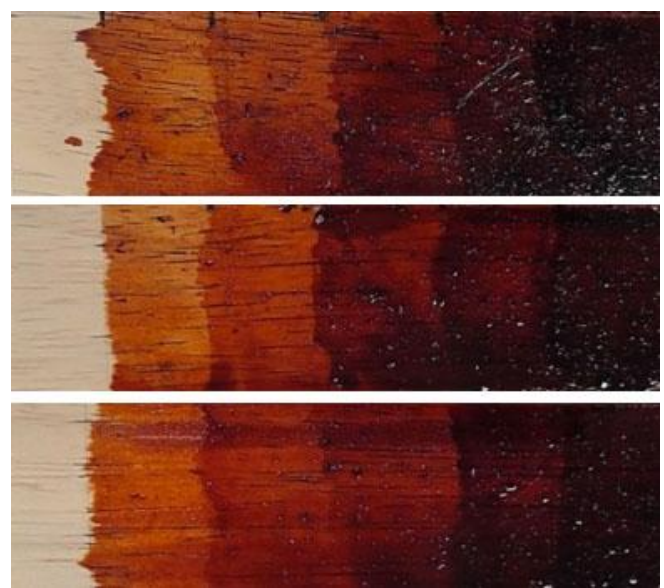

Fig. 9. Sample coated with clear lacquer and glass powder. (Top: $10 \%$, Center: $5 \%$, Bottom: $1 \%$ ).
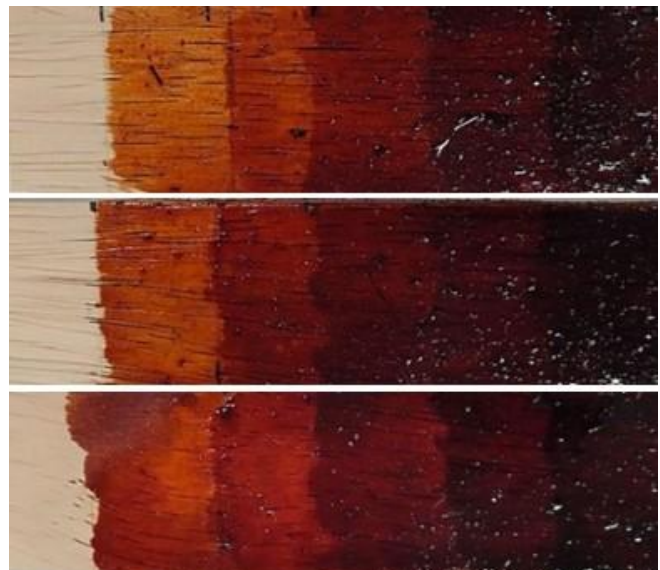

Fig. 10. Sample coated with clear lacquer and glass phosphor powder. (Top: 10\%, Center: $5 \%$, Bottom: $1 \%$ ).

\section{B. Experiment 2: Extraction of Characteristic Information}

As shown in Fig. 11, we placed each sample on a stage that could move along the X-axis; it was oriented to face the IR camera. In order to take photo of each coated film area, we prepared a mask with $35 \mathrm{~mm} \times 10 \mathrm{~mm}$ hole. Afterwards, we acquired IR images of the sample while irradiating it with laser light $(808 \mathrm{~nm})$. Each IR images were concatenated as one image shown in Fig. 12.

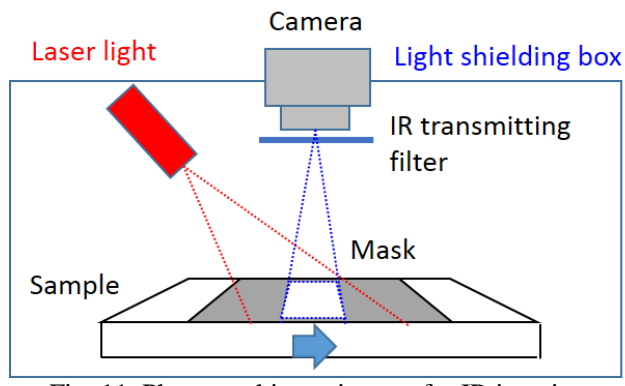

Fig. 11. Photographic equipment for IR imaging.

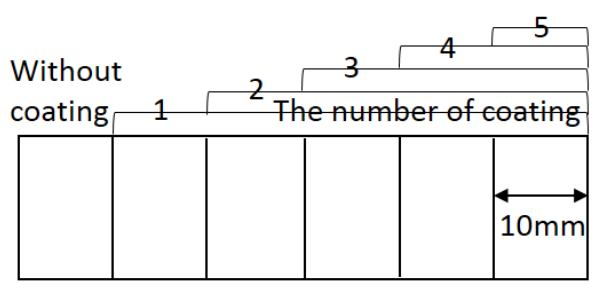

IR image string

Fig. 12. Concatenation of IR images.
1) Variation of characteristic information with number of coatings
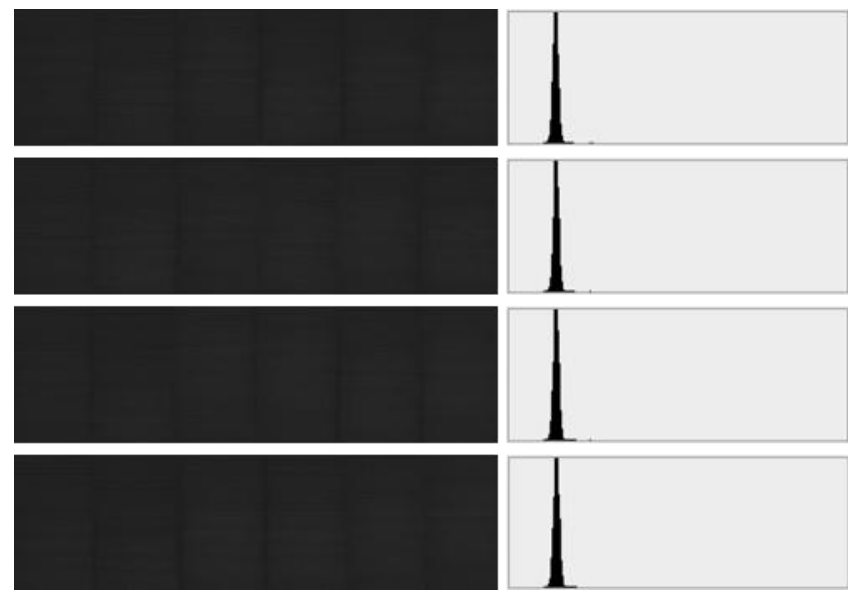

Fig. 13. IR images and histograms for Figs. 8 and 9. (Uppermost: Fig. 8, Top Fig. 9-top, Center: Fig. 9-center, Bottom: Fig. 9-bottom).

Fig. 13 shows the concatenated IR images for Figs. 8 and 9. The differences between the images are due to the different numbers of coatings, which could not be seen as the fluorescent material was not contained. No major differences between the histograms with 256 graduations are evident. Fig. 14 shows the concatenated IR images for Fig. 10. The existence of glass phosphor particles (white spots), particle density differences, and differences in the number of coatings of mixed liquid are clearly observable. It is also evident that the greater the density of glass phosphor particles in the sample, the greater the number of bright pixels in the histogram. Thus, the IR image brightness reflects the amount of glass phosphor particles.
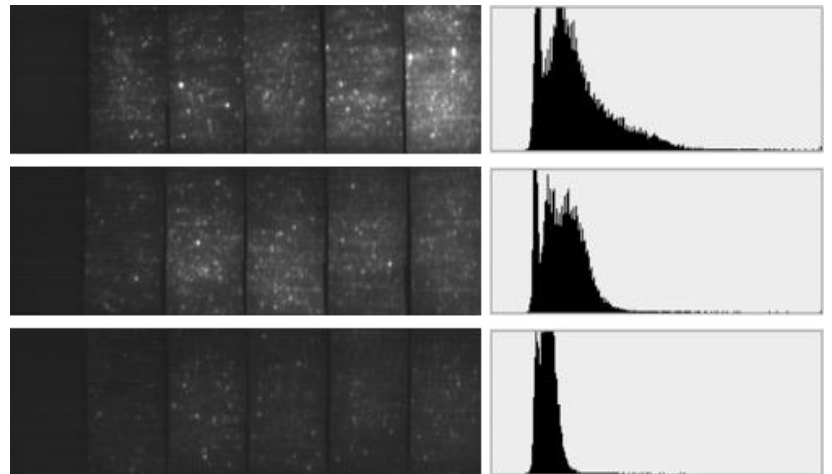

Fig. 14. IR images and histograms for Fig. 10. (Top: Fig. 10-top, Center: Fig 10-center, Bottom: Fig. 10-bottom).

\section{2) Variation of characteristic information between samples}

We prepared 10 small wooden base (height: $35 \mathrm{~mm}$, width: $20 \mathrm{~mm}$ ) and made samples that were coated with the 5\% glass phosphor five times. Fig. 15 shows the resulting IR images. Characteristic information differences are evident between the samples.

3) Variation of characteristic information with viewpoint

We obtained two IR images from one sample with the camera locate at the front and at an oblique angle of $15^{\circ}$. Fig. 16 shows the resulting IR images. As described in section 3.2, different images could be obtained by changing the camera's viewpoint. 

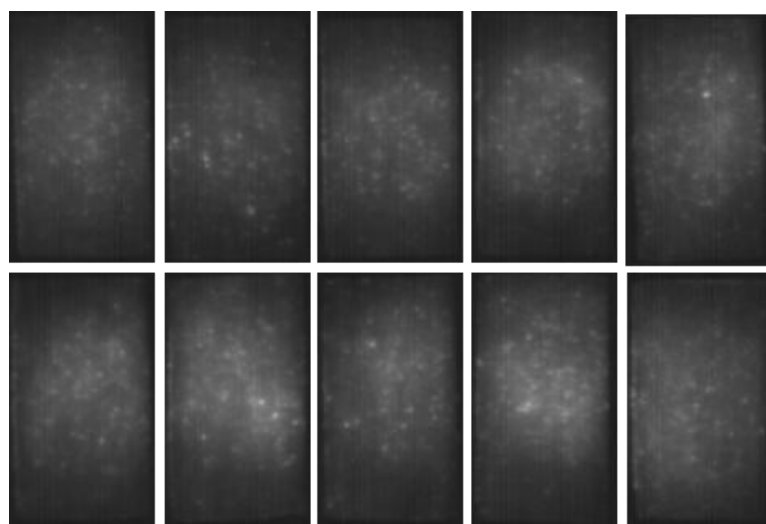

Fig. 15. IR images of 5\% phosphor
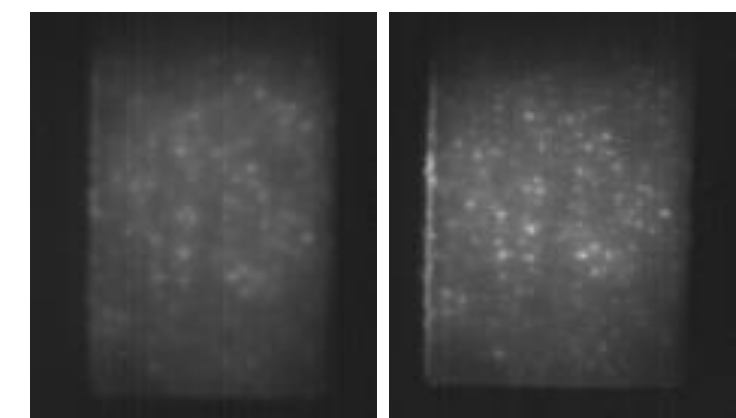

Fig. 16. IR image comparison. (Left: front, Right: oblique angle $15^{\circ}$ ).

\section{CONSIDERATION}

In this section, we consider the experimental results and the model method used in the elementary experiment. We also consider the feasibility of applying the above method to other fine craft products coated with clear lacquer liquid.

\section{A. Experimental Results}

The following observations were made in our experimental results:

1) Stability: The particles contained in the clear lacquer liquid settled in the film coating and were not removed when we rubbed the surface of the film with our fingers.

2) Impact on the color resulting from the clear lacquer liquid: When we compared samples coated by clear lacquer liquid and by $1 \%, 5 \%$, and $10 \%$ glass phosphor, no color changes between the latter three samples were observable.

3) Variation of characteristic information: We observed that the greater the density of glass phosphor particles contained in the sample, the more the IR emission intensity increased. In addition, the characteristic information varied between samples and even among different viewpoints for the same sample.

Thus, the model method used in our experiment functioned as planned, and we can conclude that the feasibility of applying the artifact-metrics technique to fine wooden lacquerware is high.

\section{B. Fine-Granulating of Particles and Feasibility of Application to Black and Colored Lacquer Liquids}

In our experiment, we produced glass phosphor powder manually by using a mortar and muddler. However, using this method, the size of the particles tended to be large (approximately $10 \mu \mathrm{m}$ or greater) so that they could be observed [8], as their size was on the borderline for fine particles that can and cannot be seen by naked eyes. In fact, we were able to see the glass phosphor particles in the coated film when we observed the samples with high concentrations of glass phosphor powder. Accordingly, fine glass phosphor powder that has the same grain size as the pigment (several micrometers) for lacquer liquid should be used in the model method to improve its efficiency. A jet mill can concretely mass-produce fine particles several micrometers in grain size in a short time [9]. We will be able to determine experimentally whether glass phosphor powder with that grain size can still emit IR light by optical excitation if we are able to obtain the characteristic information by acquiring IR images.

In our experiment, we verified the effectiveness of the model method by using clear lacquer liquid. However, in lacquerware, black and colored-pigmented lacquer liquids are also used. As such, we should confirm whether we can observe IR light by optical excitation when we coat wooden bases with each lacquer liquid with fine grass phosphor.

\section{Possibility of Application Possibility to Other Fine Craft Products}

In our experiment, the clear lacquer liquid was used to confirm the effectiveness of the model method. Clear lacquer liquid is used for other fine products, such as wood, bamboo, and paper crafts; the method described herein with clear lacquer liquid could be used to authenticate and identify these products as well. In our experiment, we were able to obtain the characteristic information from samples with one coated film formed by $1 \%$ glass phosphor. However, we think this method is not appropriate for fine products with only a few coated films, as the ability of this method to identify each product increases when more film coatings are used in the manufacturing process.

\section{CONCLUSION}

We explored the feasibility of applying the artifact-metrics technique for the authentication and identification of fine wooden lacquerware products. We proposed a model method and conducted an experiment to verify its effectiveness. In this method, clear lacquer liquid and fine particles with optical characteristics are mixed and coated on the base material several times to randomly form the characteristic information in the accumulated coated films. As the formed characteristic information can be obtained by acquiring IR images, the risk of impairing the surface of lacquerware during extraction of the said information is low. In our experiment, clear lacquer liquid and glass phosphor powder were mixed and coated on the wooden base materials to make samples. We extracted information by taking IR images of the surface of the samples using an IR camera for optical excitation. For this characteristic information, the intensity of the IR light increased in proportion to the number of coatings; it differed depending on not only the sample but also the observation angle of the same observation area. In future, we will conduct the experiment using fine glass phosphor particles several micrometers in grain diameter. We will also devise a model method for black and colored lacquer liquids and experimentally verify its effectiveness. 


\section{APPENDIX}

TABLE A-I: ARTIFACT METRICS BY USING OPTICAL CHARACTERISTICS

\begin{tabular}{|c|c|}
\hline No. & Content \\
\hline 1 & $\begin{array}{l}\text { Distribution of the photo luminescent fine particles in base } \\
\text { material (Reflected light image). [10], [11], [12], [13] }\end{array}$ \\
\hline 2 & $\begin{array}{l}\text { Distribution of the chips of optical fiber mixed into paper } \\
\text { (Distribution of the bright spots of transmitted light). [14] }\end{array}$ \\
\hline 3 & $\begin{array}{l}\text { Distribution of the spots on base material (Reflected or } \\
\text { transmitted light image). [15] }\end{array}$ \\
\hline 4 & $\begin{array}{l}\text { Distribution of the polymer fibers in clear resin (Parallax } \\
\text { image). [16] }\end{array}$ \\
\hline 5 & Distribution of the fibers in base material. [17] \\
\hline 6 & $\begin{array}{l}\text { Roughness on the surface of base material (Laser speckle } \\
\text { pattern). [18] }\end{array}$ \\
\hline 7 & $\begin{array}{l}\text { Distribution of the paper fibers on the surface of paper } \\
\text { (Reflected light image). [19] }\end{array}$ \\
\hline 8 & $\begin{array}{l}\text { Distribution of the paper fibers in paper (Transmitted light } \\
\text { image). [20] }\end{array}$ \\
\hline 9 & $\begin{array}{l}\text { Nano-artifact metrics based on silicon nanostructures formed } \\
\text { via an array of resist pillars (Reflected near-field light image) } \\
{[21],[22]}\end{array}$ \\
\hline
\end{tabular}

\section{ACKNOWLEDGMENT}

We greatly benefited from the assistance of Mr. Ikuo Takase from Fujii Urushi Kougei Corporation, as he provided detailed information regarding fine wooden lacquerware manufacturing. We also received generous support from $\mathrm{Mr}$. Noritaka Kajii from the Industrial Research Institute of Ishikawa, as he provided the information regarding pigment size in lacquer liquids.

\section{REFERENCES}

[1] R. Lane. Your online source for identifying fakes and reproductions. [Online]. Available: http://www.realorrepro.com/

[2] The Consumer Affairs Agency of Japan, Household Goods Quality Labeling Law Handbook.

[3] S. Okada, "Wakasa Obama brand certification system," Fiscal Year 2006 Report, Field Work VIII, p. 12.

[4] Y. Tamura, "The dead copy of the product produced by someone and the success and failure of the illegal act. [Online]. Available: http://lex.juris.hokudai.ac.jp/coe/articles/tamura/casenote92c.pdf

[5] Manufacturing Industries Bureau, Ministry of Economy, Trade and Industry of Japan, Butsudan-sangyo no gen-jyo to kongo no arikata ni kan-suru ken-kyu-kai hou-koku-syo (Japanese text).

[6] M. Une, Y. Tamura, and T. Matsumoto, "Gi-zo-bou-shi gi-jyu-tsu no nakano jin-kou-butsu-metrics: Security kenkyu kaihatsu no doukou to kadai (Japanese text)," Institute for Monetary and Economic Studies, Bank of Japan, 2009.

[7] M. Fujikawa, K. Moriyasu, F. Oda, S. Fuchi, and Y. Takeda, "Development of the new artifact-metrics technology for valuable pottery and porcelain products," IPSJ Journal, vol. 55, no. 9, pp. 1992-2007, Sep. 2014.

[8] H. Ashikawa. Shoku-hin-gyoukai no bi-ryu-shi sokutei (Japanse text). [Online]. Available: http://www.rion.co.jp/product/docs/04.pdf

[9] M. Inoki, "Bi-ryu-shi no kou-kinou-ka ni tai-ou shita sai-shin no fun-tai gijyu-tsu (Japanese Text)," Fun-tai, no. 57, p. 68.

[10] S. P. Ravikanth, "Physical one-way functions," Ph.D. thesis, Massachusetts Institute of Technology, 2001.

[11] L. D. Poli, Security Seal Handbook, Sandia Report, SAND 78-0400, Sandia National Laboratory, pp. 1-44, 1978.

[12] Š. Boris, G. J. Schrijen, W. Ophey, N. Verhaegh, and J. Geloven, "Experimental hardware for coating PUFs and optical PUFs," Security with Noisy Data: On Private Biometrics, Secure Key Storage and Anti-Counterfeiting, Springer-Verlag, pp. 255-268, 2007.

[13] P. Tuyls, S̆, Boris, S. Sjoerd, M. H. Akkermans, and W. Ophey, "Information-theoretic security analysis of physical uncloneable functions," in Proc. Financial Cryptography LNCS 3570, 2005, pp. $141-155$.

[14] National Research Council of the National Academies (NRC), "Counterfeit deterrent features for the next-generation currency design," Publication NMAB-472, National Academy Press, 1993, pp. 74-75.

[15] N. R. Goldman, Non-counterfeitable System, Light Signature Inc., 1988.

[16] V. Renesse and R. Leopold, "3DAS: A 3 demensional-structure authentication system," European Convention on Security and Detection, pp. 54-59, 1995.

[17] D. Brzakovic and N. Vujovic, "Authentication of random pattern by finding a match in an image database," Image and Vision Computing, vol. 14, pp. 485-499, 1996.

[18] R. D. J. Buchanan, P. R. Cowburn, A. V. Jausovec, D. Petit, P. Seem, G. Xiong, D. Atkinson, K. Fenton, A. D. F. Allwood, and T. M. Bryan, "Forgery: 'Fingerprinting' documents and packaging," Nature, vol. 436, no. 475 , p. $475,2005$.

[19] K. Ito, H. Souda, F. Ihara, T. Kimura, and M. Fuse, "Kami document no security (Japanese text)," Fuji Xerox Technical Report, no. 15, pp 36-37, 2005.

[20] M. Yamakoshi, T. Junichi, M. Furuie, M. Hirabayashi, and T. Matsumoto, "Individuality evaluation for paper based artifact-metrics using transmitted light image," in Proc. SPIE, 2008, vol. 6819, pp. $68190 \mathrm{H}-1-68190 \mathrm{H}-10$.

[21] T. Matsumoto, K. Hanaki, R. Suzuki, D. Sekiguchi, M. Hoga, Y. Ohyagi, M. Naruse, N. Tate, and M. Ohtsu, "Nano Artifact-metrics based on Resist Collapsing," IEICE Tech. Report., vol. 112, no. 461, pp. 217-222, 2013

[22] T. Matsumoto, M. Hoga, Y. Ohyagi, M. Ishikawa, M. Naruse, K. Hanaki, R. Suzuki, D. Sekiguchi, N. Tate, and M. Ohtsu, "Nano-artifact metrics based on random collapse of resist," Scientific Reports, vol. 4, no. 6142, pp. 1-5, 2014.

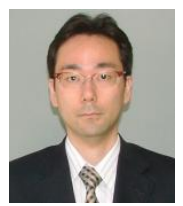

Masaki Fujikawa was born on February 6, 1974 in Tokushima Prefecture, Japan. He received his master's degree in information engineering in 1998 from Tokushima University, Tokushima Prefecture, Japan. In 2004, he received his Ph.D. in information engineering from Chuo University, Tokyo, Japan.

He joined security service company ALSOK, in Tokyo Japan in 1998. From October 2002 to March 2011, he doubled as a guest researcher of the Research and Development Initiative, Chuo University. From November 2010 to Mach 2012, he was the director of an information security R\&D project of METI (Ministry of Economy, Trade and Industry, Japan). Now, he is one of the chief researchers of his company, and researching on different security and safety systems in order to build a safer society.

Dr. Fujikawa received best paper and specially selected paper awards from IPSJ and best demonstration award from the 4th IFIP WG 11.11 International Conference on Trust Management 2010.

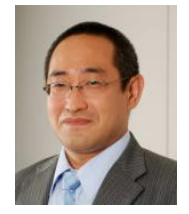

Shingo Fuchi was born in Hyogo Prefecture, Japan, in 1975. He received his master's degree and Ph.D. in materials science and engineering from Nagoya University in 1999 and 2002, respectively.

$\mathrm{He}$ is an Associate Professor in the Department of Electrical Engineering and Electronics at Aoyama Gakuin University, Sagamihara, Japan. Before coming to Aoyama Gakuin University, he was a Patent Examiner at Japan Patent Office, and an Assistant Professor in the Department of Crystalline Materials Science at Nagoya University. His research interests are semiconductor nano structure, rare-earth doped glasses, and optical device application. He has published over 40 reviewed papers. 